\title{
Experimental and Computer - Assisted Modeling of Plastic Deformation of Zircon - Based Alloys During Production of Metal Products for the Needs of the Atomic and Other Branches of Industry
}

\author{
Henryk Dyja*a, Kirill V. Ozhmegov ${ }^{\text {, }}$ \\ Anna Kawalek ${ }^{\mathrm{a}}$ and Aleksander M. Galkin ${ }^{\mathrm{b}}$ \\ ${ }^{a}$ Czestochowa University of Technology (CUT) \\ 19 Al. Armii Krajowej, Częstochowa, 42-200, Poland \\ ${ }^{b}$ National University of Science and Technology "MISIS" (MISIS) \\ 4 Leninskiy, Moscow, 119049, Russia
}

Received 20.02.2015, received in revised form 30.03.2015, accepted 26.06.2015

In this work, a task was set to study the rheological properties of zircon-based alloys with a modified chemical composition of the $\mathrm{Zr}-\mathrm{Nb}$ and $\mathrm{Zr}-\mathrm{Nb}-\mathrm{Sn}$ systems with respect to the conditions of different processes of pressure metal treatment during manufacturing of pipes and rods. For this purpose, complex plastometric tests of new grades of alloys were carried out to obtain experimental data on the deformation resistance value $\sigma p$ and maximum permissible plasticity $\Lambda p$ of these materials. The tests were carried out on a modern plastometric apparatus in a wide range of thermal mechanical conditions of deformation according to different forms of loading. On the basis of the experimental data on the mechanical properties of the materials under study, pressure metal treatment processes were developed using the Forge 2008 computer modeling software package.

Keywords: rheological properties, zirconium alloys, process modeling, metal forming.

DOI: $10.17516 / 1999-494 X-2015-8-5-609-620$.

(C) Siberian Federal University. All rights reserved

* Corresponding author E-mail address: dyja@wip.pcz.pl 


\title{
Экспериментальное и компьютерное моделирование
}

\section{пластической деформации сплавов}

на основе циркония при производстве металлопродукции

\author{
для нужд атомной
}

и других отраслей промышленности

\author{
Х. Дыя ${ }^{\mathbf{a}^{*}}$, К.В. Ожмегов ${ }^{\sigma}$, \\ А. Кавалек ${ }^{\text {a }}$ А.М. Галкин \\ "Ченстоховский политехнический университет \\ Польша 42-200, Ченстохова, Аллея Армии Краевой, 19 \\ ${ }^{6}$ НИТУ «МИСИС» \\ Россия, 119049, Москва, Ленинский проспект, 4
}

В настоящей работе поставлена задача исследования реологических свойств модифицированных по химическому составу сплавов цииркония систем $\mathrm{Zr}-\mathrm{Nb}$ и $\mathrm{Zr}-\mathrm{Nb}-\mathrm{Sn}$ применительно к условиям различных прочессов обработки металлов давлением (ОМД) при производстве труб и прутков. Для этого были выполнены комплексные пластометрические исследования новых марок сплавов с иелью получения экспериментальных данных по величине сопротивления деформации бs и предельной пластичности Ар этих материалов. Испьттания проводились на современной пластометрической установке в широком диапазоне термомеханических условий деформирования по различным законам нагружения. На основе экспериментальных данных о механических свойствах исследуемых материалов осуществлена разработка режимов технологических прочессов ОМД с использованием программного комплекса для компьютерного моделирования Forge 2008.

Ключевые слова: реологические свойства, сплавы циикония, моделирование процессов, обработка металлов давлением.

\section{Введение}

Циркониевые сплавы в настоящее время широко применяются для производства металлопроката, используемого для работы в различных отраслях промышленности. Уникальный комплекс свойств циркониевых сплавов делает их весьма привлекательными для создания продукции с высокими техническими показателями, характеристиками долговечности и надежности при работе в агрессивных средах. Благодаря небольшому сечению поглощения тепловых нейтронов, исключительной стойкости против коррозии и достаточно высоким механическим свойствам, из данных сплавов производят элементы тепловыделяющих сборок атомных электростанций. В химической и нефтеперерабатывающей отраслях промышленности из различных марок сплавов на основе циркония сооружают ответственные конструкционные узлы оборудования, работающего в высокоагрессивных средах. Цирконий и его сплавы становятся также эффективными материалами в авиации и космонавтике для производства жаропрочных покрытий деталей газотурбинных и реактивных двигателей.

Развитие атомной, химической, нефтеперерабатывающей и других отраслей промышленности ставят перед разработчиками задачи повышения уровня надежности и ресурса работы 
всех конструкционных элементов, в том числе из циркониевых сплавов, выдвигают все более высокие требования к качественным характеристикам металлопродукции, изготавливаемых из данных материалов. Под эти задачи разрабатываются новые, модифицированные по химическому составу сплавы на основе циркония. При этом на физико-механические, технологические и эксплуатационные свойства данных сплавов существенное влияние оказывает их химический состав, даже незначительные легирующие добавки и примеси [1-4].

В настоящей работе была поставлена задача исследования реологических свойств модифицированных по химическому составу сплавов циркония систем $\mathrm{Zr}-\mathrm{Nb}$ и $\mathrm{Zr}-\mathrm{Nb}-\mathrm{Sn}$ применительно к условиям различных процессов обработки металлов давлением (ОМД) при производстве труб и прутков. Для этого были выполнены комплексные пластометрические исследования новых марок сплавов с целью получения экспериментальных данных по величине сопротивления деформации $\sigma_{\mathrm{s}}$ и предельной пластичности $\Lambda_{\mathrm{p}}$ этих материалов. Испытания проводились на современной пластометрической установке в широком диапазоне термомеханических условий деформирования по различным законам нагружения. На основе экспериментальных данных о механических свойствах исследуемых материалов осуществлялась разработка режимов технологических процессов ОМД с использованием программного комплекса для компьютерного моделирования «Forge «2008».

\section{Материал и методика исследований}

При исследовании реологических свойств модифицированных циркониевых сплавов системы $\mathrm{Zr}-\mathrm{Nb}$ и $\mathrm{Zr}-\mathrm{Nb}-\mathrm{Sn}$ использовали методы испытаний на сжатие и растяжение, в каждом из которых выявляли отдельные качества металла, характерные для данного метода. Пластометрические испытания осуществляли на пластометре «Gleeble 3800», причем испытания на сжатие проводили на цилиндрических образцах Ø10×12 мм, а на растяжение - на образцах Ø10×116 мм. Стоит отметить, что испытания на растяжение на пластометре «Gleeble 3800» имели ту методическую особенность, что рабочая часть испытываемых образцов определяется длиной зоны их локализованного нагрева и составляет 20 мм [5].

Для физического моделирования процессов пластической обработки модифицированных циркониевых сплавов были определены основные параметры каждого процесса и их возможный диапазон изменения. В итоге реологические исследования циркониевых сплавов проводились в широком температурно-скоростном диапазоне при $\mathrm{T}=20-950{ }^{\circ} \mathrm{C}, \dot{\varepsilon}=0,1-15 \mathrm{c}^{-1}$ и соответствовали промышленным условиям свободной и радиальной ковки, прессования и прокатки при производстве труб и прутков. При пластометрических испытаниях на пластометрах «Gleeble 3800» нагрев образцов осуществлялся прямым пропусканием электрического тока с регулируемой скоростью нагрева образцов $5{ }^{\circ} \mathrm{C} / \mathrm{c}$. Тмпературу образцов при пластометрических испытаниях контролировали с помощью хромель-копелевой термопары, привариваемой к центральной части образца. Термопара выполняла роль не только контроля температуры, но и управления скоростью нагрева и охлаждения испытываемого образца. Высокая чувствительность системы контроля температуры на установке «Gleeble 3800» позволяла в процессе испытаний замерять тепловой эффект пластической деформации.

В качестве смазки при испытаниях на сжатие применяли тонкие прокладки на основе графита. Рабочие бойки типа ISO-T после каждого испытания дополнительно смазывали графи- 
товой смазкой марки OKS 255. Для предотвращения окисления и газонасыщения поверхности испытываемых образцов при их нагреве использовали вакуум. Охлаждение образцов после испытаний осуществлялось со скоростью $10^{\circ} \mathrm{C} / \mathrm{c}$ при помощи обдува инертным газом, а при необходимости фиксации структуры металла - душированием водой. При помощи программного обеспечения Microsoft Office Excel эти результаты обрабатывали и строили диаграммы «температура-напряжение-деформация».

Диаграммы предельной пластичности $\Lambda_{\mathrm{p}}$ при испытаниях образцов на растяжение были построены по методике В.Л. Колмогорова [6]. В случае однородной деформации (до образования шейки) предельная степень деформации (предельная пластичность) определялась через относительное удлинение $\delta$ :

$$
\Lambda_{P}=1,73 \ln [100 /(100-\delta)],
$$

а для неоднородной деформации в случае образования шейки на образце - через относительное сужение $\psi$ :

$$
\Lambda_{P}=1,73 \ln [100 /(100-\psi)] .
$$

Предельную степень деформации сдвига $\Lambda_{\mathrm{p}}$ при сжатии находили соотношением

$$
\Lambda_{P}=\sqrt{3} \ln \left(h_{0} / h_{P}\right) \text { при }\left(\sigma_{\mathrm{cp}} / \tau_{i}\right)_{c p}=-0,5,
$$

где $h_{0}$ - исходная высота образца; $h_{P}$ - высота образца в момент разрушения; $\sigma_{c p}$ - среднее напряжение; $\tau_{i}-$ интенсивность сдвиговых напряжений.

Аппроксимирующая обработка результатов пластометрических исследований и компьютерное моделирование выполняли в приложении программы Forge 2008® «RheologyDatabase» в Институте процессов ОМД и инженерии безопасности Ченстоховского политехнического университета.

\section{Результаты исследований}

Как видно на рис. 1, с ростом температуры испытаний коэффициент деформационного упрочнения сплава $\mathrm{Zr}$ - Nb снижается и на кривых течения всё более заметно проявляются процессы динамического разупрочнения. Кинетика прохождения в металле процесса динамического возврата и динамической рекристаллизации в значительной мере определяется положением максимума на кривых $\sigma_{S}-\bar{\varepsilon}$. С увеличением температуры деформации и снижением скорости этот максимум все больше смещается в область меньших степеней деформации, что заметно в температурном диапазоне испытаний $580-770{ }^{\circ} \mathrm{C}$. Участок установившегося течения $\sigma_{S}=\sigma_{y c m}$ проявляется на кривых, полученных при температурах 700 и $770{ }^{\circ} \mathrm{C}$, до степени деформации $\bar{\varepsilon}<0,4$. Положение максимума на кривых течения определяет величину $\bar{\varepsilon}_{X}-$ характеристическую степень деформации, когда стадия $d \sigma_{S} / d \bar{\varepsilon}>0$ переходит в стадию $d \sigma_{S} / d \bar{\varepsilon}<0$, т.е. процессы разупрочнения интенсифицируются и превалируют над процессами деформационного упрочнения. При этом кривые $\sigma_{S}-\bar{\varepsilon}$ имеют куполообразную форму. Подобная форма кривых течения указывает, что с ростом температуры процессы динамического разупрочнения играют все возрастающую роль благодаря значительному увеличению скорости диффузионных процессов во всем интервале $\mathrm{T}_{\text {исп }}$. 




Рис. 1. Кривые деформационного упрочнения сплава $\mathrm{Zr}-\mathrm{Nb}$ при испытаниях на растяжение на пластометре «Gleeble 3800». Температура, ${ }^{\circ} \mathrm{C}: 1-580 ; 2-650 ; 3-700 ; 4-770$
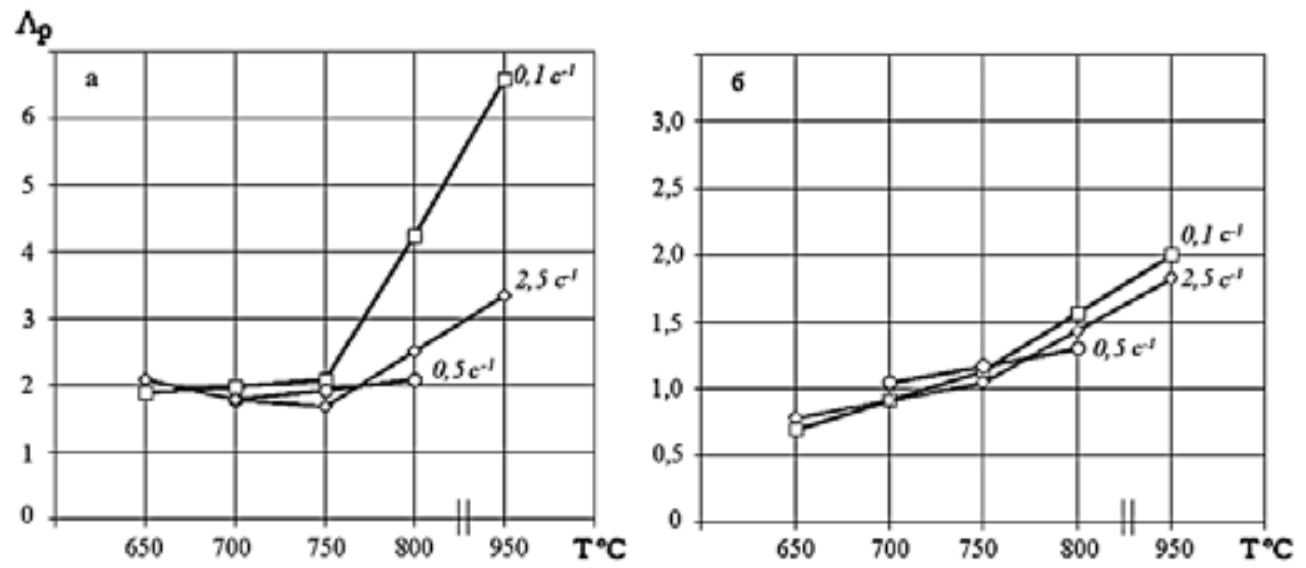

Рис. 2. Влияние температуры и скорости деформации на предельную пластичность при испытаниях сплава системы $\mathrm{Zr}$ - $\mathrm{Nb}$ на растяжение: a - расчет через параметр $\delta$; б - расчет через параметр $\psi$

На рис. 2 мы видим, что с ростом $\mathrm{T}_{\text {исп }}$ от 650 до $950^{\circ} \mathrm{C}$ предельная пластичность $\Lambda_{\mathrm{p}}$ сплава $\mathrm{Zr}-\mathrm{Nb}$ изменяется неоднозначно. При скорости деформации $\dot{\varepsilon}=0,1 \mathrm{c}^{-1}$ предельная пластичность у сплава возрастает при расчёте как через параметр $\psi$, так и через параметр $\delta$. При скорости деформации $\dot{\varepsilon}=2,5 \mathrm{c}^{-1}$ при расчете через параметр $\psi$ наблюдается провал пластичности до $\mathrm{T}_{\text {исп }}=750{ }^{\circ} \mathrm{C}$. В диапазоне $\mathrm{T}_{\text {исп }}=650-680{ }^{\circ} \mathrm{C}$ и скорости деформации $\dot{\varepsilon}=2,5 \mathrm{c}^{-1}$ уровень предельной пластичности у сплава выше, чем при скорости деформации $\dot{\varepsilon}=0,1 \mathrm{c}^{-1}$. Это объясняется тепловым эффектом, который увеличивает локализацию пластического течения в шейке образца и пластичность сплава.

Значительная разница между значениями предельной пластичности, рассчитанными через параметры $\psi$ и $\delta$, объясняется неравномерностью деформации в продольном и поперечном направлениях. 
На рис. 3, 4 представлены кривые течения $\sigma_{S}-\bar{\varepsilon}$ сплавов $\mathrm{Zr}-\mathrm{Nb}$ и $\mathrm{Zr}-\mathrm{Nb}-\mathrm{Sn}$ при непрерывном нагружении образцов в интервале $\mathrm{T}_{\text {исп }} 20-950{ }^{\circ} \mathrm{C}$ и $\dot{\varepsilon}$ от $0,1 \mathrm{c}^{-1}$ до $15 \mathrm{c}^{-1}$. При комнатной температуре деформационное упрочнение более заметно проявляется у сплава системы $\mathrm{Zr}-\mathrm{Nb}-\mathrm{Sn}$. Для него также при $20{ }^{\circ} \mathrm{C}$ и скорости деформации $\dot{\varepsilon}=15 \mathrm{c}^{-1}$ в области больших деформаций $(\bar{\varepsilon}>0,4)$ характерно интенсивное снижение величины $\sigma_{S}$, связанное с проявлением теплового эффекта пластической деформации. В целом при комнатной температуре уровень кривых течения сплавов $\mathrm{Zr}-\mathrm{Nb}$ - Sn выше, чем у сплава $\mathrm{Zr}$ - Nb. Коэффициент деформационного упрочнения для обоих сплавов при $\mathrm{T}_{\text {исп }}=20^{\circ} \mathrm{C}$ с ростом степени деформации заметно снижается, поскольку стадия единичного, а затем и множественного скольжения переходит на параболический участок и нарушается постулат Друккера. В области $\bar{\varepsilon}=0,3-0,4$ отношение $d \sigma_{S} / d \bar{\varepsilon}$ становится равным нулю, а затем и отрицательным $\left(d \sigma_{S} / d \bar{\varepsilon}<0\right)$. Это явление вообще

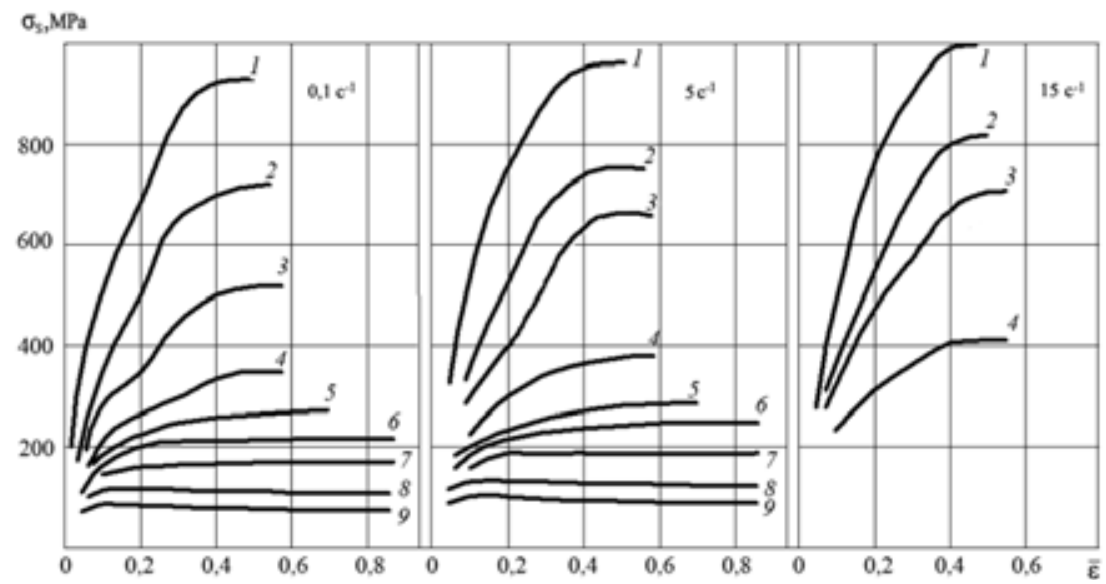

Рис. 3. Кривые деформационного упрочнения сплава $\mathrm{Zr}-\mathrm{Nb}-\mathrm{Sn}$ при испытаниях на сжатие на пластометре «Gleeble 3800». Температура, ${ }^{\circ} \mathrm{C}: 1$ - 20; 2 - 200; 3 - 350; 4 - 500; 5- 580; 6 - 650; 7 - 770; $8-850 ; 9-950$

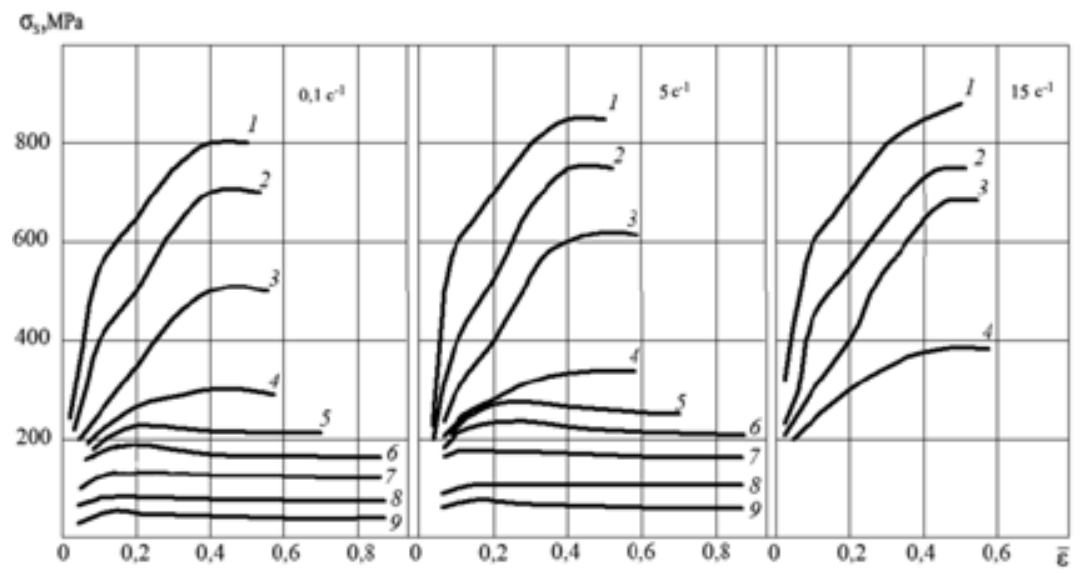

Рис. 4. Кривые деформационного упрочнения сплава $\mathrm{Zr}-\mathrm{Nb}$ при испытаниях на сжатие на пластометре «Gleeble 3800». Температура, ${ }^{\circ} \mathrm{C}: 1-20 ; 2-200 ; 3-350 ; 4-500 ; 5-580 ; 6-650 ; 7-770 ; 8-850 ; 9-950$ 
характерно именно для металлов и сплавов системы ГПУ. Данные материалы отличаются не только значительным тепловым эффектом в условиях холодной и теплой деформации с большими скоростями, но и ярко выраженной анизотропией свойств с проявлением текстурной неоднородности.

При переходе к $\mathrm{T}_{\text {исп }}=200^{\circ} \mathrm{C}$ характер кривых течения обоих сплавов меняется мало. Можно отметить, что при скоростях $\dot{\varepsilon}=0,1-0,5 \mathrm{c}^{-1}$ и с ростом степени деформации кривые течения данных сплавов явно выходят на стадию установившегося течения $\sigma_{S}=\sigma_{y c m}$. При этом значения $\sigma_{S}$ сплавов $\mathrm{Zr}-\mathrm{Nb}$ и $\mathrm{Zr}-\mathrm{Nb}-\mathrm{Sn}$ в исследованном скоростном диапазоне располагаются в одном и том же интервале $\sigma_{S}=600-800$ МПа. При дальнейшем росте температуры область деформационного упрочнения исследованных сплавов сокращается и при $\mathrm{T}_{\text {исп }}=500{ }^{\circ} \mathrm{C}$ стадия установившегося течения начинается уже при $\bar{\varepsilon} \geq 0,3-0,5$. Скоростное упрочнение в диапазоне $\mathrm{T}_{\text {исп }} 350-500{ }^{\circ} \mathrm{C}$ у сплава $\mathrm{Zr}-\mathrm{Nb}-\mathrm{Sn}$ проявляется более заметно, особенно при $\mathrm{T}_{\text {исп }}=350^{\circ} \mathrm{C}$.

В интервале $\mathrm{T}_{\text {исп }}$ от 500 до $580{ }^{\circ} \mathrm{C}$ у сплавов $\mathrm{Zr}-\mathrm{Nb}$ и $\mathrm{Zr}-\mathrm{Nb}-\mathrm{Sn}$ отмечался куполообразный характер кривых течения с весьма протяженным участком установившегося течения, что явно указывает на начало протекания процессов динамического возврата. При деформации, предшествующей стадии $\sigma_{S}=\sigma_{y c m}$ в металле образуется ячеистая структура. Степень деформации, при которой начинает формироваться такая структура, тем меньше, чем выше температура и ниже скорость деформации. В области больших деформаций на стадии установившегося течения структура металла приобретает все более равновесный характер со сравнительно невысокой плотностью дислокаций. В температурном интервале горячей деформации $\left(\mathrm{T}_{\text {исп }}=650-950{ }^{\circ} \mathrm{C}\right)$ и скоростном диапазоне от $0,1 \mathrm{c}^{-1}$ до $15,0 \mathrm{c}^{-1}$ максимум значений $\sigma_{S}$ смещается в область малых значений степени деформации $(\bar{\varepsilon} \approx 0,1-0,2)$ и выражен уже не так ярко. На кривых течения наблюдается участок установившегося течения $\sigma_{S}=\sigma_{y c m}$. С повышением температуры этот участок становится все более протяженным.

Из сравнения кривых течения сплавов $\mathrm{Zr}-\mathrm{Nb}$ и $\mathrm{Zr}-\mathrm{Nb}-\mathrm{Sn}$ видно, что в исследованном температурно-скоростном диапазоне кривые $\sigma_{S}-\bar{\varepsilon}$ в целом имеют сходный характер. В температурном интервале от $20{ }^{\circ} \mathrm{C}$ до $300{ }^{\circ} \mathrm{C}$ оба сплава характеризуются высоким уровнем деформационного упрочнения. В температурном интервале от 500 до $950{ }^{\circ} \mathrm{C}$ на кривых течения обоих сплавов наблюдается стадия установившегося течения, что существенно упрощает использование опытных данных по сопротивлению деформации для широкого интервала деформационных условий нагружения исследованных сплавов. Во всех случаях кривые течения сплава $\mathrm{Zr}$ - Nb - Sn проходят выше кривых сплава $\mathrm{Zr}$ - Nb, однако с ростом температуры эта разница становится менее заметной. Стоит также отметить, что оба сплава характеризуются резким снижением величины $\sigma_{S}$ в диапазоне $\mathrm{T}_{\text {исп }}$ от $20^{\circ} \mathrm{C}$ до $500{ }^{\circ} \mathrm{C}$. В то же время в диапазоне $\mathrm{T}_{\text {исп }}$ от 650 до $950{ }^{\circ} \mathrm{C}$ у обоих сплавов кривые течения по уровню значений $\sigma_{S}$ отличаются значительно меньше.

Предельную пластичность $\Lambda_{P}$ при сжатии цилиндрических образцов Ø10×12 мм определяли по формуле 3. Ввиду того что бочкообразование образцов при осадке на пластометре «Gleeble 3800» было незначительным, коэффициент напряженного состояния металла $K_{i}$ на поверхности осаживаемого образца в первом приближении принимался равным величине $K_{c p}$. Как видно на рис. 5,6 , предельная пластичность сплавов $\mathrm{Zr}-\mathrm{Nb}$ и $\mathrm{Zr}-\mathrm{Nb}-\mathrm{Sn}$ с ростом тем- 
пературы монотонно возрастает. Влияние скорости деформации на предельную пластичность неоднозначно. В диапазоне температур от 20 до $650{ }^{\circ} \mathrm{C}$ при высоких скоростях ( $\dot{\varepsilon}$ от 5 до $15 \mathrm{c}^{-1}$ ) значительное влияние на предельную пластичность оказывает тепловой эффект, поэтому кривые пластичности при данных скоростях проходят выше кривой при скорости $\dot{\varepsilon}=0,1 \mathrm{c}^{-1}$. В интервале $\mathrm{T}_{\text {исп }}=650-950{ }^{\circ} \mathrm{C}$ влияние теплового эффекта уменьшается и с повышением скорости деформации пластичность снижается. В целом стоит отметить, что в исследованном температурно-скоростном диапазоне уровень значений предельной пластичности сплава $\mathrm{Zr}$ $\mathrm{Nb}$ незначительно выше, чем у сплава $\mathrm{Zr}-\mathrm{Nb}-\mathrm{Sn}$.

\section{Пластометрическое и компьютерное моделирование дробного нагружения}

При получении полуфабрикатов из циркониевых сплавов первой технологической операцией цикла обработки металлов давлением является многопереходная ковка заготовок на ги-

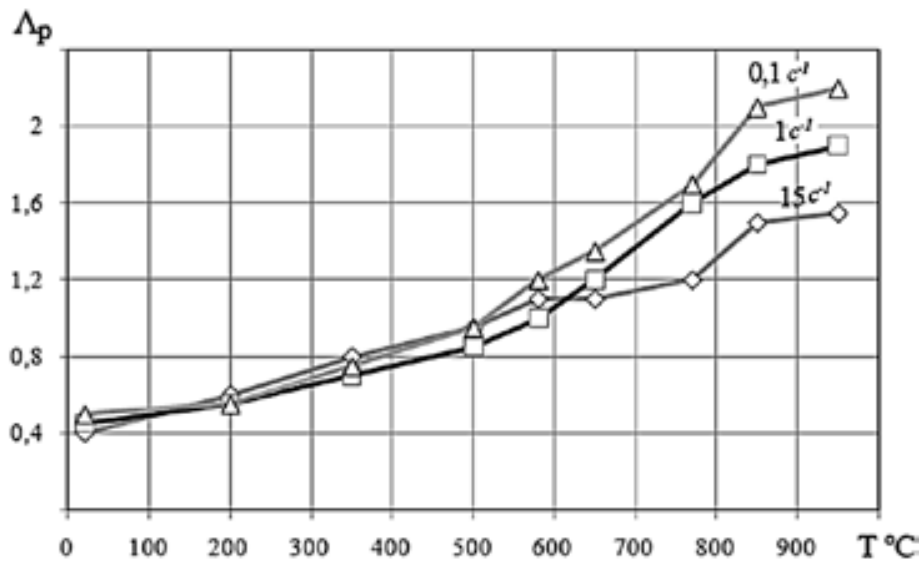

Рис. 5. Влияние температуры и скорости деформации на предельную пластичность сплава $\mathrm{Zr}-\mathrm{Nb}$ в диапазоне $\mathrm{T}_{\text {исп }} 20-950{ }^{\circ} \mathrm{C}$ при испытаниях на сжатие

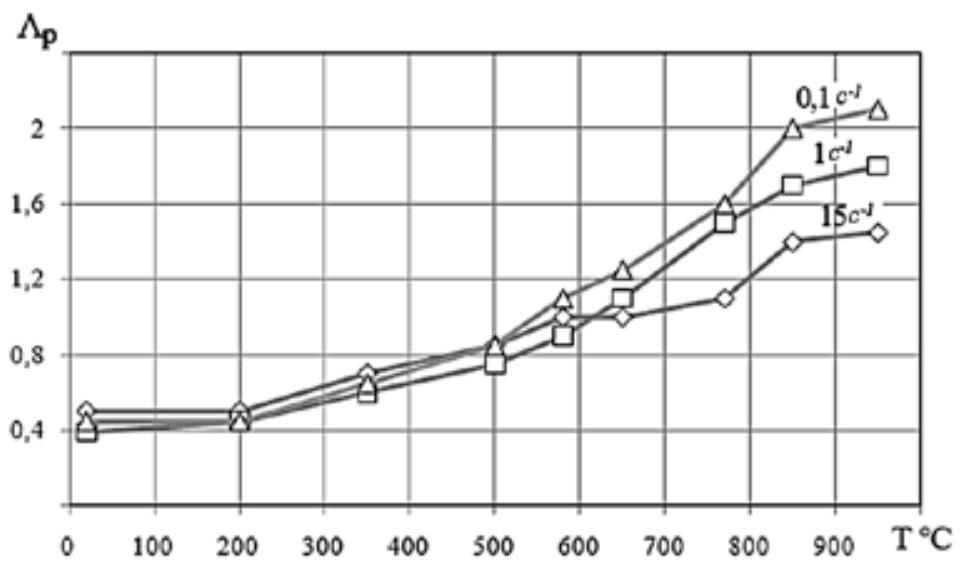

Рис. 6. Влияние температуры и скорости деформации на предельную пластичность сплава $\mathrm{Zr}-\mathrm{Nb}-\mathrm{Sn}$ в диапазоне $\mathrm{T}_{\text {исп }} 20-950^{\circ} \mathrm{C}$ при испытаниях на сжатие 
дравлических прессах в условиях горячей деформации. С учетом схемы напряженного состояния и активного газонасыщения поверхностных слоев деформируемого металла в процессе ковки определяющее значение играет правильный выбор термомеханических режимов горячей деформации. С одной стороны, для раздробления литой структуры и снижения физикомеханической неоднородности металла требуются повышенные единичные и суммарные обжатия заготовок. С другой - излишне повышенные обжатия ( $\bar{\varepsilon}>0,3)$ неизбежно приводят к внедрению («замешиванию») газонасыщенных и окисленных поверхностных слоев металла в глубь заготовок. А это крайне отрицательно влияет на качество полуфабрикатов из циркониевых сплавов, получаемых на последующих технологических операциях прессования, радиальной ковки и прокатки [7].

В работе представлены результаты физического и компьютерного моделирования процесса горячей ковки слитка Ø450 мм из циркониевого сплава системы $\mathrm{Zr}-\mathrm{Nb}-\mathrm{Sn}$ в заготовку квадратного сечения 190×190 мм на гидравлическом прессе усилием $12 \mathrm{MH}$. Моделировались режимы ковки по заводской технологии и опытный режим с измененным распределением единичных обжатий и температур деформируемого металла по проходам.

Заводской режим ковки цииркониевого сплава системы $\mathrm{Zr}-\mathrm{Nb}-\mathrm{Sn}$

Нагрев образцов до $950{ }^{\circ} \mathrm{C}$, выдержка 5 мин, охлаждение до $918{ }^{\circ} \mathrm{C}$ (с учетом переноса слитка к прессу). Ниже приведено распределение обжатий и температуры деформируемого слитка по проходам (всего 21 проход).

Величина обжатия. $\bar{\varepsilon}_{i}: 0,12-0,12-0,12-0,12-0,12-0,12-0,12-0,11-0,11-0,11-0,1-$ $0,1-0,1-0,1-0,1-0,1-0,1-0,1-0,1-0,1-0,1(\Sigma \bar{\varepsilon}=2,27)$.

Температура. $\mathrm{T}_{\text {исп }}$ : $918-917-915-912-909-905-901-897-892-886-880-874-868-$ $862-856-848-840-832-822-811-800$. Скорость охлаждения металла между проходами задавалась $0,2{ }^{\circ} \mathrm{C} / \mathrm{c}$, средняя скорость деформации по проходам принималась $\dot{\varepsilon}=0,5 \mathrm{c}^{-1}$. Паузы между проходами составляли: 5 - 10 - 15 - 15 - 20 - 20 - 20 - 25 - 30 - 30 - 30 - 30 - 30 - 30 $40-40-40-50-55-55$.

Опытный режим ковки с более интенсивным распределением обжатий по проходам (всего 17 проходов)

Величина обжатий. $\bar{\varepsilon}_{i}: 0,16-0,16-0,15-0,15-0,14-0,14-0,13-0,12-0,14-0,14-0,13-$ $0,13-0,12-0,12-0,12-0,11-0,11(\Sigma \bar{\varepsilon}=2,27)$

Температура. $\mathrm{T}_{\text {исп }}$ : 918 - 917 - 915 - 912 - $909-905-901-897-892-887-881-875-$ $869-961-852-842$ - 832. Скорость охлаждения металла между проходами и средняя скорость деформации по проходам задавались аналогично заводскому режиму, а паузы составляли: 5 $10-15-15-20-20-20-25-25-30-30-30-40-45-50-50$. Величина суммарной (накопленной) деформации для обоих режимов ковки была одинаковой: $\Sigma \bar{\varepsilon}=2,27$.

Как видно на рис. 7, распределение величины сопротивления деформации $\sigma_{S}$ исследуемого сплава по проходам, а значит, и усилия ковки, по заводской технологии весьма неравномерное. В первых проходах величина $\sigma_{S}$ лежит в диапазоне 30-37 МПа, но с восьмого прохода начинает монотонно расти, достигая уровня 80-90 МПа в последних проходах. При этом характер изменения сопротивления деформации данного сплава на первых 7-8 проходах напоминает класси- 
ческие кривые течения $\sigma_{S}-\bar{\varepsilon}$, характерные для процесса динамической рекристаллизации [2]. В начальной стадии (в области $\bar{\varepsilon}=0,2-0,3$ ) наблюдается четко выраженный максимум значений $\sigma_{S}$ с последующим выходом на стадию установившегося течения $\left(\sigma_{S}=\sigma_{y c m}\right)$. Затем начиная со значений $\bar{\varepsilon}=0,7-0,8$ происходит монотонный рост величины сопротивления деформации, связанный с падением температуры металла от прохода к проходу вплоть до температуры окончания процесса ковки $\left(\mathrm{T}_{\text {исп }}=800{ }^{\circ} \mathrm{C}\right)$. Из рис. 7 становится очевидным, что по заводскому режиму первые проходы оказались явно недогруженными, тогда как в конце цикла ковки усилие резко возрастает, повышая и неравномерность деформации на последних проходах. Это стало основанием для проведения корректировки режима ковки слитков из исследуемого сплава за счет перераспределения единичных обжатий по всему циклу деформации.

По опытному режиму (рис. 8) величина единичных обжатий в первых проходах была повышена до значений $\bar{\varepsilon}=0,14-0,16$ с последующим монотонным снижением $\bar{\varepsilon}$ до 0,1 в последнем проходе. За счет этого стало возможным сокращение обжатий с 21 по заводской технологии до 17 по экспериментальному режиму.

При этом сократилось время цикла ковки и снизилось падение температуры металла поковки. Уровень значений величины $\sigma_{S}$ исследуемого сплава по опытному режиму ковки вплоть до 15-го прохода лежит в диапазоне 40-50 МПа (рис. 8). Лишь в двух последних проходах величина $\sigma_{S}$ достигает уровня 60 МПа. Интересно также отметить, что по опытному режиму ковки минимальный уровень значений $\sigma_{S}$ наблюдается в 3-5-м проходах $(\bar{\varepsilon}=0,4-0,8)$, где наиболее интенсивно идет процесс динамической рекристаллизации. Этот процесс и определяет характер кривых дробной деформации в последующих проходах. С 9-го и вплоть до 14-го прохода на кривых $\sigma_{S}-\bar{\varepsilon}$ четко проявляется максимум значений $\sigma_{S}$ в начальной стадии нагружения.

Характер кривых течения по опытному режиму (рис. $9 a$ ) указывает на то, что можно добиться ещё более равномерного распределения величины $\sigma_{S}$ по циклу ковки. Желательно снизить величину единичных обжатий в первых двух проходах, а также в проходах 16-17.

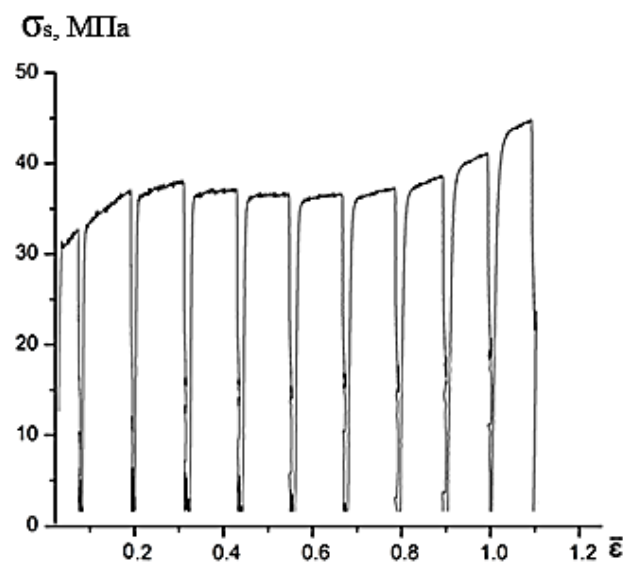

a

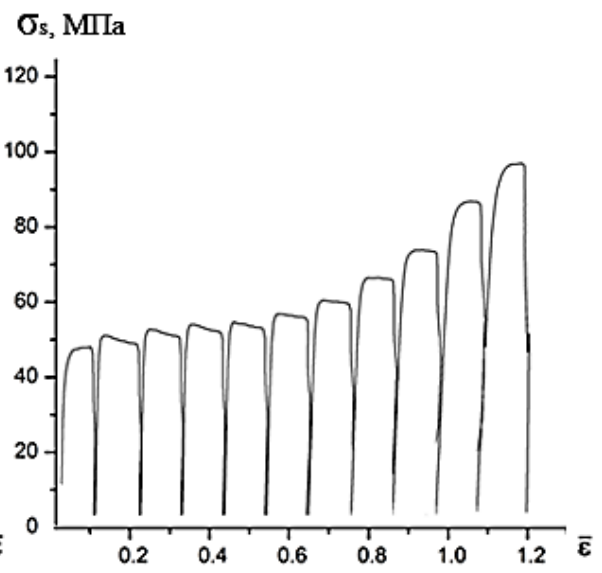

6

Рис. 7. Кривые распределения величины $\sigma_{\mathrm{S}}$ по проходам процесса ковки слитка циркониевого сплава системы $\mathrm{Zr}-\mathrm{Nb}$ - Sn размером Ø450 мм в заготовку сечением 190×190 мм в 1-10 проходах (а) и в 11-21 проходах (б) по заводской технологии 


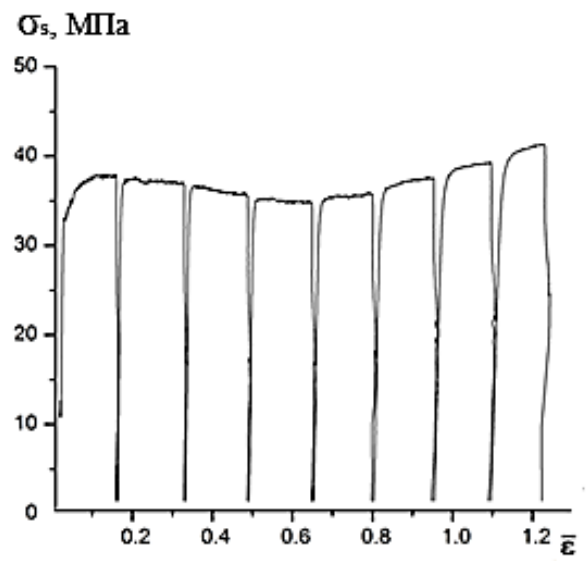

a

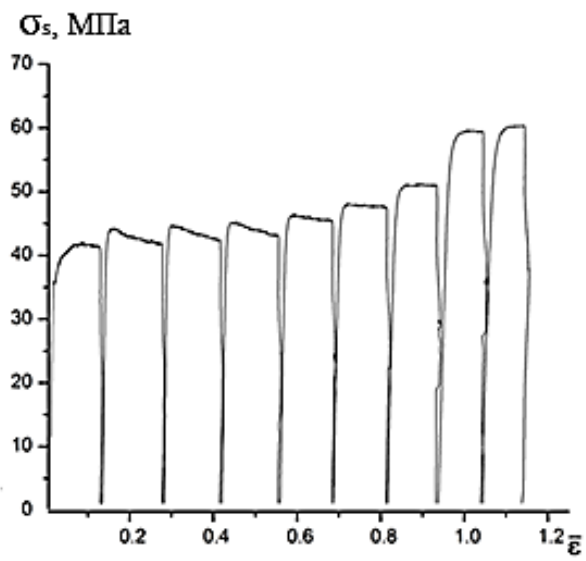

6

Рис. 8. Кривые распределения величины $\sigma_{\mathrm{S}}$ по проходам процесса ковки слитка сплава $\mathrm{Zr}-\mathrm{Nb}-\mathrm{Sn}$ размером Ø450 мм в заготовку сечением 190×190 мм в 1-8 проходах (а) и в 9-17 проходах (b) по экспериментальному режиму в 17 проходов

При этом соответственно незначительно увеличить единичные обжатия в проходах 4-5 и 9-14. Перераспределение единичных обжатий по опытному режиму позволило не только интенсифицировать пластическую деформацию сплава, но и увеличить проработку осевой части слитка. На рис. 96 приведено сравнение результатов компьютерного моделирования существующего и опытного режимов. Результаты моделирования подтверждают наличие в осевой части слитка растягивающих напряжений на уровне 50-70 МПа (рис. 9б, вар. 1). Увеличение разовых обжатий и обеспечение условия, при котором относительная подача $\mathrm{k}$ находится в диапазоне $0,5 \leq \mathrm{k} \leq 0,8$, повышает степень проработки осевой зоны слитка, что видно на рис. 96, вариант 2. Уровень действия растягивающих напряжений в осевой части слитка остался примерно на том же уровне, однако зона их распространения уменьшилась примерно в два раза.

\section{Выводы}

1. Реологические исследования, выполненные на современной пластометрической установке методами испытаний на сжатие и растяжение, позволили определить зависимости сопротивления деформации $\sigma_{\mathrm{s}}$ и предельной пластичности $\Lambda$ р модифицированных циркониевых сплавов марок $\mathrm{Zr}-\mathrm{Nb}$ и $\mathrm{Zr}-\mathrm{Nb}-\mathrm{Sn}$ от термомеханических параметров холодной, теплой и горячей деформации. Сравнительный анализ кривых течения исследованных сплавов показал в целом их сходный характер, но при заметном отличии по уровню значений $\sigma_{\mathrm{s}}$ и $\Lambda \mathrm{p}$.

2. На основании результатов физического (пластометрического) моделирования были получены технологические рекомендации по перераспределению величины единичных обжатий в условиях многоступенчатой горячей ковки заготовок квадратного сечения 190×190 мм из сплавов на основе циркония. Было установлено, что увеличение единичных обжатий в первых проходах до величины $\bar{\varepsilon}_{i}=0,14-0,16$ с монотонным их снижением к концу цикла ковки позво- 



6

Рис. 9. Результаты экспериментального и компьютерного моделирования ковки слитка из сплава $\mathrm{Zr}$ - Nb - Sn размером Ø450 мм в заготовку сечением 190×190 мм; 1-й вариант по заводской технологии, 2-й вариант по опытному режиму: а - кривые распределения величины $\sigma_{\mathrm{S}}$ по проходам ковки; б - напряжённое состояние в слитке при первом проходе

ляет снизить энергетические затраты, повысить производительность технологического оборудования и качественные показатели получаемых поковок.

3. Компьютерное моделирование процесса свободной ковки слитков из циркониевых сплавов системы $\mathrm{Zr}$ - Nb - Sn подтвердило результаты физического моделирования о необходимости повышения интенсивности единичных обжатий в первых проходах с соответствующим сокращением цикла обработки поковок. При этом величина относительной подачи рекомендуется в диапазоне $0,5 \leq \mathrm{k} \leq 0,8$, что позволяет снизить вероятность образования осевой пористости в деформируемой заготовке.

\section{Список литературы}

[1] Полухин П.И., Гун Г.Я., Галкин А.М. Сопротивление пластической деформации металлов и сплавов. М.: Металлургия, 1983. $351 \mathrm{c.}$

[2] Галкин А.М. Никулин А.Д., Бочаров О.В., и др. // Цветные металлы. 1997. № 3. С. 32-35.

[3] Галкин А.М., Синельников Д.Д., Никулин А.Д. и др. // Цветные металлы. 1998. № 3. C. 14-17.

[4] Galkin A. Badania plastometryczne metali i stopów. Częstochowa: Politechnika Częstochowska. 1990. C. 142.

[5] Dyja H., Gatkin A., Knapiński M. Reologia Metali Odkształcanych Plastycznie. Częstochowa: WPCz. 2010. № 190. C. 371.

[6] Dyja H., Gałkin A., Knapiński M., Ozhmegov K. // Hutnik Wiadomości Hutnicze. 2010. № 5. C. 207-209.

[7] Gałkin A.M., Ożmiegow K.W., Kawałek A. // Hutnik Wiadomości Hutnicze. 2012. № 12. C. 916-919. 